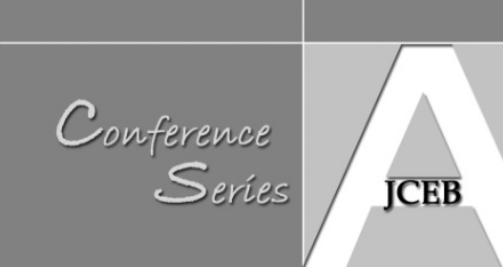

\title{
Procurement Selection Model: Development of a Conceptual Model Based on Transaction Costs
}

\author{
Mohammed A. Rajeh, John Tookey, James Rotimi (Auckland University of \\ Technology, New Zealand)
}

\begin{abstract}
Procurement is a major improvement area and a crucial element contributing to project success, and the selection of an optimal procurement system is an important and difficult step in project execution. The criteria for choosing suitable procurement methods are based on client's objectives and priorities, and influenced by project constraints. The procurement path determination chart has largely dominated research in procurement selection process in construction. Eight factors need to be considered by the client when developing procurement selection criteria. At the procurement strategy the focus should be on factors such as cost, quality, and time, while at the procurement route the consideration should focus on complexity, certainty, risk, responsibility, and degree of control by the client. However, including certain criteria and ignoring the magnitude of transaction costs (TCS) associated with uncertainties in the transaction environment simplifies this process. This study addresses this shortcoming by combining evaluation criteria with TCs incurred because of external and internal environmental uncertainties in a theoretical model on procurement selection. This is achieved by developing a conceptual framework model based on TCs. Uncertainties in the transaction environment have a positive or negative impact on the magnitude of TCs such as information, procurement, administration, and enforcement. The model represents an analytical form of a suitable combination of factors influencing procurement systems, which guide procurement decisions. The model will increase understanding of how efficient procurement selection of construction projects can be achieved through appropriate procurement procedures, which could positively impact project performance.
\end{abstract}

Keywords: Construction, Procurement systems, Transaction costs

\section{Introduction}

Operational performance continues to raise interest in the construction industry. The procurement process provides opportunities to cut costs and boost profit, and thus achieve a competitive advantage for the firm. Added to this, a proper procurement system affects the success or failure of any project. Several procurement forms have been conceived to match client/ community requirements, the most common are Traditional, Design and Build, Management, Alliance, BOOT, and Concession (Brook, 2008; Murdoch \& Hughes, 2008). Generally, selecting a suitable procurement system relies heavily on a project's constraints i.e. cost, time, and quality, along with other factors such as the size and complexity of the project (Chinyio, 2011).

Researchers have developed several theoretical models for the procurement selection process in construction (NEDO, 1985; Franks, 1990; Singh, 1990; Kumaraswamy \& Dissanayaka, 1998; Alhazmi \& McCaffer, 2000; Cheung et al., 2001). The idea behind these models is to improve the decision-making process in selecting the most appropriate procurement system. Heide and John (1990) contend that the Transaction Cost Theory (TCT) provides a useful framework for the selection of the most applicable procurement system for projects. This paper combines a firm's environmental uncertainties in the 
procurement selection process. The paper presents a conceptual model for the selection of the most applicable procurement system based on TCs. The developed model could help decision-makers in cutting costs and improving productivity.

\section{Transaction Costs in Construction}

Ronald Coase first introduced the TCs concept in 1937. Williamson (1985) went further to develop the TCT by focusing on the economic actors' behavioral assumptions (opportunism and bounded rationality) and transaction characteristics such as specificity, uncertainty, and number of bargaining. Economic actors behaving opportunistically with bounded rationality and uncertainties dominate contracts, which partially accounts for contingencies. The contingencies are costs borne by unforeseen events surrounding a transaction. Such as information, negotiation, competitive advantage, contract administration and management, market structure, enforcement, and measuring/monitoring performance, collectively referred to as TCs (Heide \& Stump, 1995; Artz, 1999; Melese \& Franck, 2005).

Procurement systems implemented on any project have a significant impact on the TCs associated with the pre and post-contract phases. In Figure 1, Pre-contract costs relate to activities carried out during initiation, preliminary design, negotiation and contracting, feasibility studies, and environmental uncertainties evaluations. According to Whittington (2008), a study of public/private partnership projects (PPPs), pre-contract transaction costs in projects procured using Traditional systems may amount to between $0.4 \%$ and $8.8 \%$ of the value of the contract. While for projects procured using Design-Build systems, the TCs may amount to between $0 \%$ and $5.7 \%$.

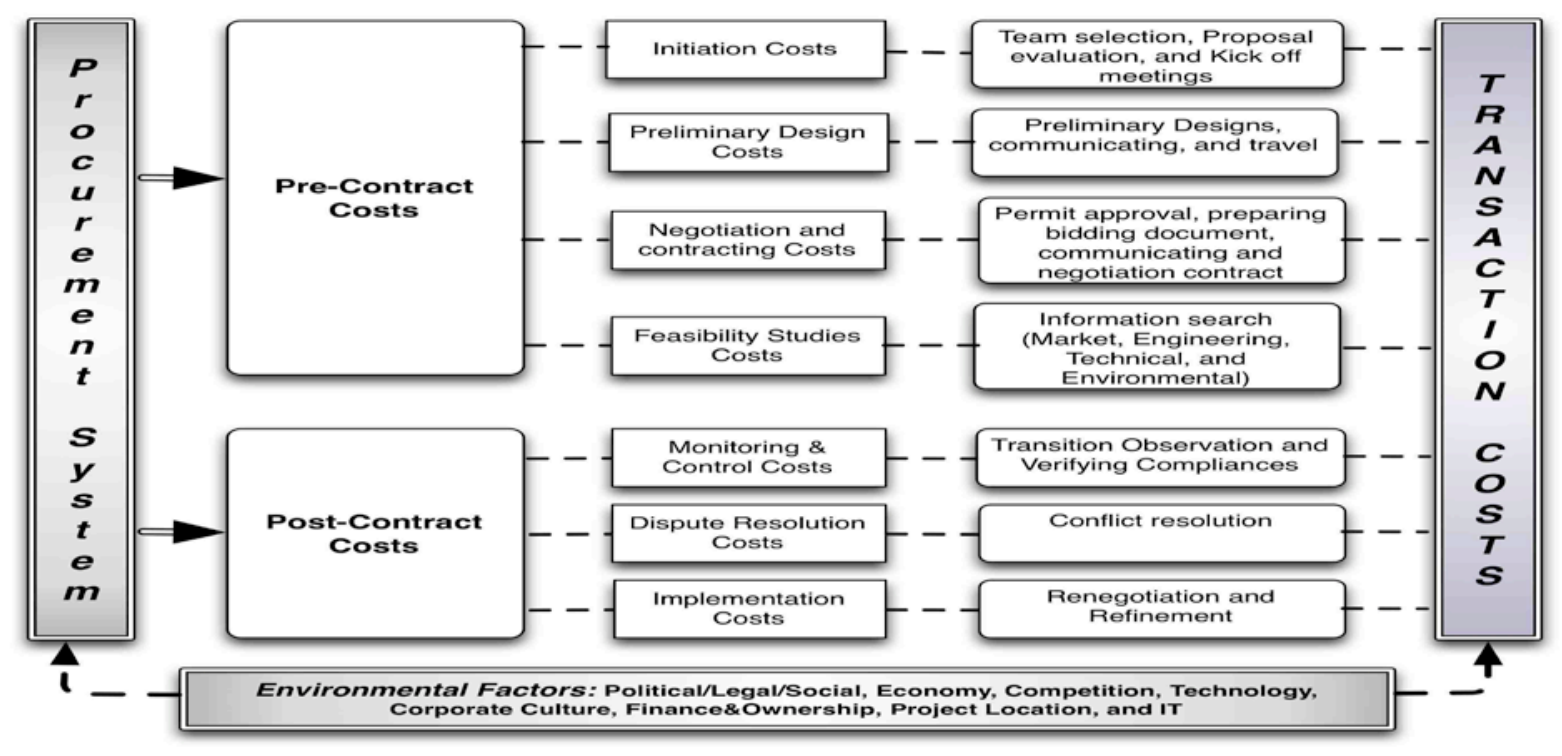

Figure 1: Delineation of TC activities in construction procurement systems

Post-contract costs are commonly associated with monitoring and control, dispute resolution, and implementation activities for projects. In countries such as Australia, the UK and USA, conflicts and disputes could inflict a high cost on the construction industry (Li et al., 2012), while the situation is similar in New Zealand. Whittington's (2008) study in the US PPPs projects shows that in a Traditional procurement system, post-contract TCs may

Rajeh, M.A, Tookey, J \& Rotimi, J. 2014, 'Best procurement selection: development of a conceptual model based on transaction costs’, Australasian Journal of Construction Economics and Building Conference Series, 2(2), 56-63. 
amount to between $8.9 \%$ and $14.7 \%$ of contract value; while for a Design-Build system it ranges between $3.4 \%$ and $14.3 \%$ of the contract value.

There have been only a few studies trying to quantify TCs, although the concept of TCs has received substantial attention by researchers and academics. The concept of TC's is applied in several areas within construction, such as; contracting and sub-contracting agreements, buyer-supplier relationships (Eccles 1981; Gunnarson and Levitt 1982; Reve and Levitt 1984; Winch 1989; Alsagoff and McDermott 1994; Turner and Simister 2001; Bajari and Tadelis 2001), project delivery systems and project governance (Lynch 1996; Walker and Wing 1999; Winch 2001; Whitington 2008), transaction costs evaluation (Dudkin and Valila 2005; Chang and Ive 2007; Solino and Gago de Santos 2009; Farajian 2010), and risk allocation strategies (Jin and Zhang 2011).

This study aims to fill the gaps found between existing researches through developing a model for selecting the most applicable procurement system based on TCs. Two procurement systems are used for comparison: Traditional and Design-Build. Environmental uncertainties affect pre and post contract transaction costs. In this research, external TCs such as conflict and disputes costs e.g. lawyers and court costs are ignored and are out of the scope of this research.

\section{Environmental Uncertainties in Construction}

Environmental uncertainties refer to institutions or forces outside the organizations that potentially affect the organization's performance. Political, legal, social, economical, competition, and technology refer to external uncertainties. While corporate culture, project location, finance, and ownership, and information systems represent internal uncertainties (Williamson, 1985; Wright \& Race, 2004). Uncertainties affect the ability of contracting parties to fully specify the range of contingencies for unforeseen events that may disturb the success of the Project. Consequently it becomes more costly to write a fully specified contract (Williamson, 1985; Brouthers \& Nakos, 2004). According to TCT, the key factors in generating TCs are bounded rationality in the face of uncertainty and complexity; and opportunism in the context of small numbers of bargaining (Williamson, 1981).

Duncan (2009) posits that lump sum and cost reimbursement systems were the procurement trend during the post-war regeneration (1946-1969). During the 1970-1979 period of high inflation, an increasing preponderance of clients started to use management contracting in order to save some money (Duncan, 2009). Meanwhile the sub-prime market collapse in 2009 was reported to have caused a shift in procurement trend to design-build (Duncan, 2009). Brochner (1990) suggested IT improves coordination between team members, quality control/product inspection, and translation of the needs of the client. Other determinants of procurement systems include: corporate culture (Wright \& Race, 2004), market competition, technology (Schermerhorn et al., 2002; Duncan, 2009), project location (Hughes et al., 2006), financial circumstances and project ownership. These factors are depicted in Figure 2.

Rajeh, M.A, Tookey, J \& Rotimi, J. 2014, 'Best procurement selection: development of a conceptual model based on transaction costs’, Australasian Journal of Construction Economics and Building Conference Series, 2(2), 56-63. 


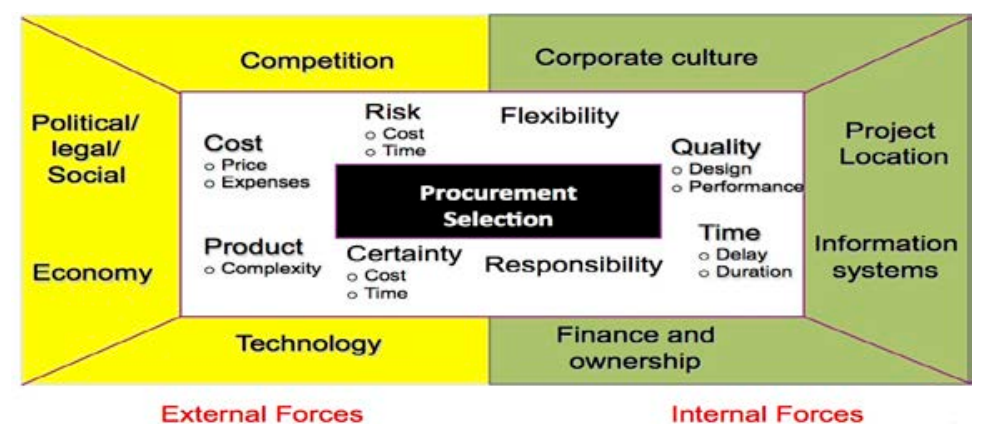

Figure 2: The Determinants of procurement systems

\section{Research Methodology}

The Transaction Cost Theory (TCT) focuses on the interrelationship between human and environmental factors. Human factors for example; opportunism and bounded rationality have a substantial effect on the customer-supplier relationship in the context of a contractual agreement. Environmental uncertainties influence the execution of contractual agreements and the construction process.

The following are the hypotheses developed based on the conceptual framework described previously:

o Transaction costs are significantly higher if political, legal, social, and economic uncertainties are high.

o Transaction costs are high if competition and technology uncertainties are high.

o Finance and ownership, site location, corporate culture, and information systems have low effect on transaction costs.

The determinants of TCs that incurred due to environmental uncertainties are presented in Table 1. These determinants were used to validate and test hypotheses. The magnitude of TCs is determined from information provided by professionals while conducting procurement activities during project phases (procured under traditional and Design-build systems).

Table 1: Determinant of TCs

\begin{tabular}{|l|l|}
\hline Magnitude of TCs & \\
\hline Pre-Contract TCs & $\begin{array}{l}\text { Include costs relate to activities carried out during initiation, preliminary design, } \\
\text { negotiation and contracting, and feasibility studies (Heide \& Stump, 1995; Artz, 1999; } \\
\text { Melese \& Franck, 2005). }\end{array}$ \\
\hline Post-Contract TCs & $\begin{array}{l}\text { Commonly costs associated with monitoring and control, dispute resolution, and } \\
\text { implementation (Heide \& Stump, 1995; Artz, 1999; Melese \& Franck, 2005). }\end{array}$ \\
\hline Uncertainties in the Transaction Environment \\
\hline External Uncertainties & Represent external forces i.e. threats and opportunities for the firm. \\
\hline Political/Legal/Social & $\begin{array}{l}\text { A number of federal Laws, Political stability of the host country, and Social } \\
\text { responsibilities. For example, federal laws set up the mechanisms for implementing } \\
\text { the contractual agreements (Wright 2004, Elliot 2008). Uncertainties of these factors } \\
\text { may increase the transaction costs. }\end{array}$ \\
\hline Economy & $\begin{array}{l}\text { Inflation, exchange rate, and market situation are factors that influenced the choice of } \\
\text { management contracting (Duncan 2009). High inflation and market uncertainties } \\
\text { increase the transaction cost. }\end{array}$ \\
\hline Competition & $\begin{array}{l}\text { This includes the number of bidders during the tendering process. Low number of } \\
\text { bidders creates a less competitive procurement process that may contribute in reducing } \\
\text { pre contract transaction costs but may increase opportunism (Farajian 2010). }\end{array}$ \\
\hline Technology & Improves the coordination between project team members, quality control, and \\
\hline
\end{tabular}

Rajeh, M.A, Tookey, J \& Rotimi, J. 2014, 'Best procurement selection: development of a conceptual model based on transaction costs’, Australasian Journal of Construction Economics and Building Conference Series, 2(2), 56-63. 


\begin{tabular}{|l|l|}
\hline & $\begin{array}{l}\text { translation of client needs (Brochner 1990). Using improved technology such as } \\
\text { CAD/CAM software's may lead to transaction costs reduction. }\end{array}$ \\
\hline Internal Uncertainties & Represent internal forces i.e. weakness and strength of the firm. \\
\hline Corporate Culture & $\begin{array}{l}\text { Strong culture means individual know how things are done and expected. In this } \\
\text { situation it may lead to minimizing the transaction costs associated with shirking, } \\
\text { poaching, etc. (Wright 2004). }\end{array}$ \\
\hline Project Location & $\begin{array}{l}\text { The project location augments costs of logistics, which lead to increase in transaction } \\
\text { costs. }\end{array}$ \\
\hline Finance \& Ownership & $\begin{array}{l}\text { Increase the likelihood of vertical financial ownership may increase the transaction } \\
\text { costs (Williamson 1985). }\end{array}$ \\
\hline Information Systems & $\begin{array}{l}\text { Information system may have a direct effect on external and internal coordination } \\
\text { costs and operational costs. Adopting IT in the construction operation may decrease } \\
\text { the transaction costs (Vijay and Seungjing 1991). }\end{array}$ \\
\hline
\end{tabular}

A causal loop model (see Figure 3 ) is developed based on the determinants shown in table 1 , to examine direct and indirect relationships between any independent variables and any dependent variables. The independent variables represent the latent variables, e.g. environmental factors, information cost, procurement cost, administration cost, and enforcement cost. The relationship between the latent variables is explained through the direction of the paths between the variables and the strength of the path coefficients. For example in traditional procurement systems, there is a strong positive correlation between environmental uncertainties and information cost while in design-build procurement systems this correlation is positively neutral. Moreover, in design-build procurement systems there is a strong positive correlation between environmental uncertainties and enforcement cost while in traditional procurement systems this correlation is positively neutral. Analogously, other correlations between environmental uncertainties, procurement costs, and administration cost would be measured. Further, the amount measures of these correlations will be determined in the later stage of this study.

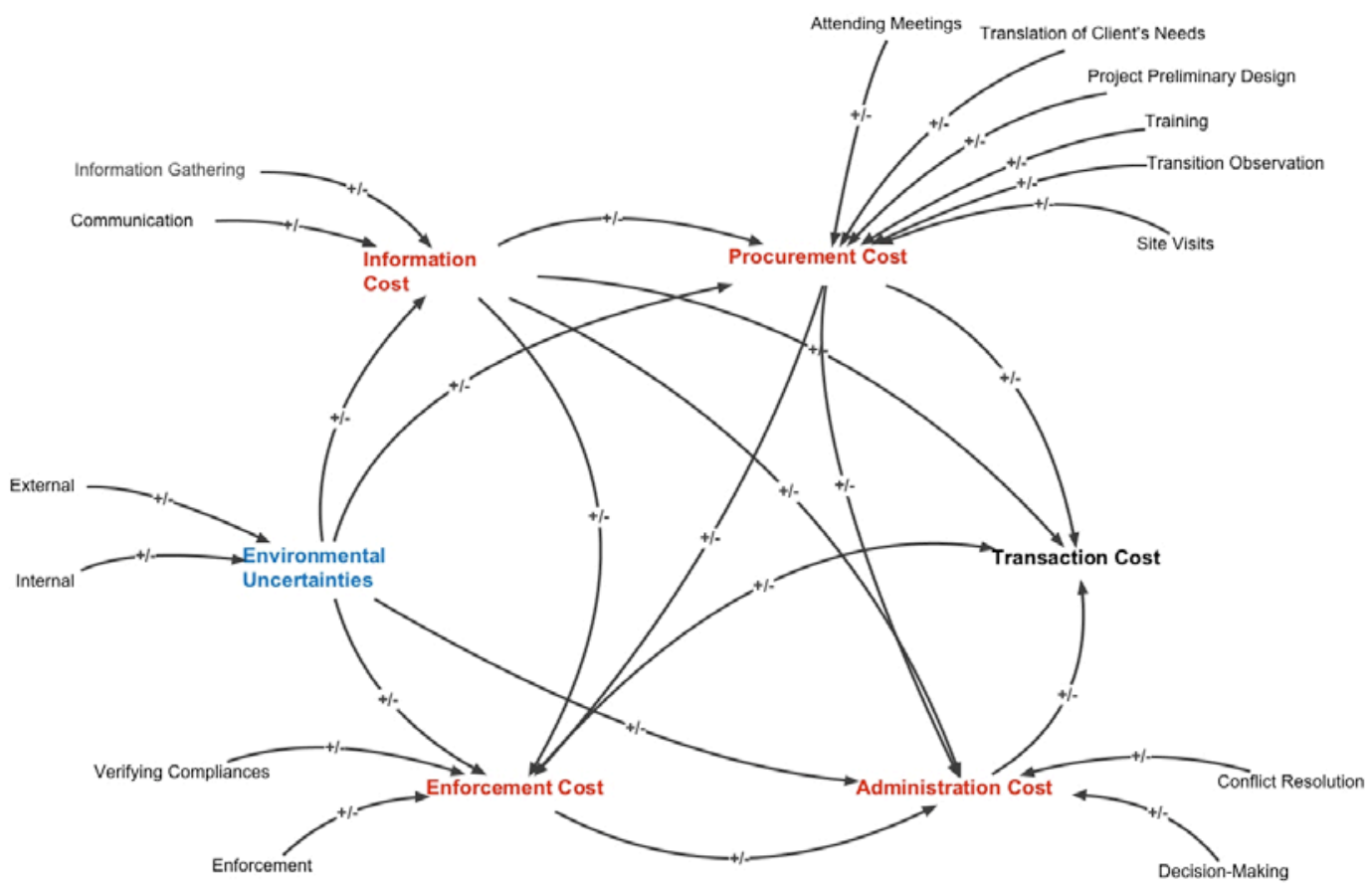

Figure 3: Causal loop diagram

Rajeh, M.A, Tookey, J \& Rotimi, J. 2014, 'Best procurement selection: development of a conceptual model based on transaction costs’, Australasian Journal of Construction Economics and Building Conference Series, 2(2), 56-63. 


\section{Discussion}

To develop a theoretical model for procurement selection in line with Williamson (1998) wherein human and environmental forces were considered the most important contributory factors to TCs; cognitive mapping and causal loop diagrams were used to depict and interpret the various factors highlighted in table 1 above.

This study addresses the reliability of the constructs in table 1 by developing a causal loop diagram (Figure 3), and to test the three hypotheses mentioned previously. For example in traditional procurement systems, the hypothesis that the TCs are significantly higher if political, legal, social, and economic uncertainties are high is significant. This is because there is a strong positive correlation between environmental uncertainties and the components contributing to TCs (i.e. cost of information, procurement, and enforcement) as shown in figure 3. Accordingly, in order to develop a proper procurement selection process, the client should be prepared to deal with political/legal/social uncertainties in the transaction environment, and to account for higher TCs by making sure the cost estimate for contingencies is as covered as possible. Researchers such as (Mitropoulos \& Howell, 2001; Walker \& Pryke, 2009; Love et al., 2010) also supported the extensive effect uncertainties in the transaction environment. Also, other hypotheses will be tested and analyzed in the same way.

\section{Conclusion}

Researchers have developed several theoretical models for the procurement selection in construction (NEDO, 1985; Skitmore \& Marsden, 1988; Franks, 1990; Singh, 1990; Kumaraswamy \& Dissanayaka, 1998; Alhazmi \& McCaffer, 2000; Chan et al., 2001; Cheung et al., 2001). These models generally do not address environmental uncertainties surrounding a firm. Uncertainty in the transaction environment and its impact on TCs emanates to be the core construct in developing a model for the procurement selection. This paper introduces the potential for the use of TCT for determining the magnitude of TCS for different procurement systems in construction. This is achievable by determining the costs associated with the pre and post contract phases (e.g. information, procurement, administration, and enforcement). Pre and post contract transaction costs will be determined in the next stage of this study through developing a path analysis model or structural equation model (SEM) utilizing the statistical software by IBM SPSS 20 and its modeling plug-in Amos 21. In which structural and measurement models will be used to determine: firstly, the existence of a single latent independent variable as a result of a set of measurement items; secondly, the relationship between the latent variable and observed variables by means of the path direction and coefficients strength.

Finally, by developing a model for procurement selection based on TC's could help to improve the procurement phase through: firstly, identifying the service goals, objectives and priorities through better contractual agreements; secondly, identifying capacity development requirements through enhanced long-term strategic procurement approaches; thirdly, ensuring adequate funding through improved cost estimation; and finally, defining the most feasible contractual approach under certain circumstances.

\section{References}

Alhazmi, T \& McCaffer, R. 2000, 'Project Procurement System Selection Mode', Journal of Construction Engineering \& Management, 126(3), 176-84.

Rajeh, M.A, Tookey, J \& Rotimi, J. 2014, 'Best procurement selection: development of a conceptual model based on transaction costs’, Australasian Journal of Construction Economics and Building Conference Series, 2(2), 56-63. 
Artz, K. W. 1999, 'Buyer-Supplier Performance: The Role of Asset Specificity, Reciprocal Investments and Relational Exchange', British Journal of Management, 10(2), 113-26.

Brook, M. 2008, Estimating and Tendering for Construction Work (4th ed.). Butterworth-Heinemann, London.

Brouthers, K. D \& Nakos, G. 2004, 'SME Entry Mode Choice and Performance: A Transaction Cost Perspective', Entrepreneurship Theory and Practice, 28(3), 229-47. doi:10.1111/j.15406520.2004.00041.x

Chan, A. P. C, Yung, E. H. K, Lam, P. T. I, Tam, C. M \& Cheung, S. O. 2001, 'Application of Delphi method in selection of procurement systems for construction projects', Construction Management and Economics, 19(7), 699-718. doi:10.1080/01446190110066128

Cheung, S, Lam, T, Leung, M \& Wan, Y. 2001, 'An analytical hierarchy process based procurement selection method', Construction Management and Economics, 19(4), 427-37. doi:10.1080/014461901300132401

Chinyio, E. 2011, The Cost of Tendering. presented at the meeting of the Engineering Project Organisations, Colorado, USA.

Duncan, C. 2009, Quantity Surveyor's Pocket Book (First ed.). ELSEVIER, Oxford, UK.

Franks, J. 1990, Building Procurement Systems. Chartered Institute of Building, Englemere, Kings Ride, Ascot, UK.

Heide, J. B \& Stump, R. L. 1995, 'Performance implications of buyer-supplier relationships in industrial markets: A transaction cost explanation', Journal of Business Research, 32(1), 57-66. doi:10.1016/0148-2963(94)00010-c

Hughes, W. P, Hillebrandt, P, Greenwood, D. G \& Kwawu, W. E. K. 2006, Procurement in the Construction Industry: The impact and cost of alternative market and supply processes. Taylor and Francis, London.

Kumaraswamy, M. M \& Dissanayaka, S. M. 1998, 'Linking procurement systems to project priorities;, Building Research \& Information, 26(4), 223-38. doi:10.1080/096132198369832

Li, H, Arditi, D \& Wang, Z. 2012, 'Transaction-related issues and construction project performance', Construction Management and Economics, 30(2), 151-64. doi:10.1080/01446193.2012.655254

Love, P, Davis, P, Ellis, J \& Cheung, S. O. 2010, 'Dispute causation: identification of pathogenic influences in construction', Engineering, Construction and Architectural Management, 17(4), 404-23. doi:http://dx.doi.org/10.1108/09699981011056592

Melese, F \& Franck, R. 2005, 'A Transaction Cost Economics View of DOD Outsourcing', Presented at the 2nd Annual Acquisition Research Symposium of the Naval Postgraduate School, California.

Mitropoulos, P \& Howell, G. 2001, 'Model for understanding, preventing, and resolving project disputes', Journal of Construction Engineering \& Management, 127(3), 223-31.

Murdoch, J \& Hughes, W. 2008, Construction Contracts: Law and Management (4th ed.), Taylor \& Francis, London.

NEDO 1985, Thinking about Building, National Economic Development Office, HMSO, London.

Schermerhorn, R. J, Hunt, G. J \& Osborn, N. R. 2002, Organizational Behavior (7th ed.), John Wiley \& Sons, New York.

Rajeh, M.A, Tookey, J \& Rotimi, J. 2014, 'Best procurement selection: development of a conceptual model based on transaction costs', Australasian Journal of Construction Economics and Building Conference Series, 2(2), 56-63. 
Singh, S. 1990, 'Selection of appropriate project delivery system for construction projects', CIB W-90 International Symposium on Building Economics and Construction Management, Sydney, Australia.

Skitmore, M \& Marsden, E. 1988, 'Which procurement systems? Towards a universal procurement selection technique', Construction Management \& Economics, 6(1), 71-89.

Walker, A \& Pryke, S. 2009, 'Role, Dimensions, and Degrees of Incompleteness in Construction Contract Documentation', Proceedings of the RICS Annual Construction, Building and Real Estate Research Conference, Cape Town, South Africa.

Williamson, O. E. 1981, 'The Economics of Organization: The Transaction Cost Approach', American Journal of Sociology, 87(3), 548-77.

Williamson, O. E. 1985, 'Assessing Contract', Journal of Law, Economics, \& Organization, 1(1), 177208.

Wright, J. N \& Race, P. 2004, The Management of Service Operations (2nd Ed.), Thomson London.

Rajeh, M.A, Tookey, J \& Rotimi, J. 2014, 'Best procurement selection: development of a conceptual model based on transaction costs', Australasian Journal of Construction Economics and Building Conference Series, 2(2), 56-63. 